\title{
OPEN A magnetic copper organic framework material as an efficient and recyclable catalyst for the synthesis of 1,2,3-triazole derivatives
}

\author{
Elham Arefi, Amir Khojastehnezhad \& Ali Shiri ${ }^{凶}$ \\ In this study, a core-shell magnetic metal organic framework (MOF) catalyst was introduced based on \\ $\mathrm{Fe}_{3} \mathrm{O}_{4}$ magnetic nanoparticles (MNPs) and copper organic frameworks. In this catalyst, $\mathrm{Fe}_{3} \mathrm{O}_{4} \mathrm{MNPs}$ \\ have been coated with MOFs in which copper was the inorganic nodes and 1,3,5-benzenetricarboxylic \\ acid was the organic linkers. Then, the core-shell structures and catalytic efficiency have been \\ confirmed properly and completely with various analyses such as FT-IR, TEM, SEM, TEM mapping, \\ SEM mapping, EDX, PXRD, TGA, ICP and VSM. The Cu moieties in MOF and shell structures can \\ catalyze the synthesis of 1,2,3-triazole derivatives with good to excellent yields in the presence \\ of water as a green solvent. Moreover, this catalyst showed the high reusability due to the super \\ paramagnetic properties.
}

One of the best nanomaterials that have been recently gained huge attention for immobilization of different organic and inorganic ligands are MNPs and especially $\mathrm{Fe}_{3} \mathrm{O}_{4}{ }^{1-7}$. Due to the nanostructures, particle size, and morphology, they showed high magnetic properties, however, these magnetic capacities cause the serious aggregation that is one of the most significant restrictions ${ }^{8,9}$. For problem-solving, design the magnetic supports with core-shell structures can prepare the high-dispersed MNPs ${ }^{10-16}$. Thus, the best strategy is the coating MNPs with various inorganic and organic substances including carbon based materials, silica, alumina, polymers, and $\mathrm{MOFs}^{17-21}$. These nanostructures can be considered as shell structures to decrease the aggregation of MNPs.

MOFs are a unique types of crystalline substances with network and porous structures ${ }^{22}$. They have huge internal surface areas (beyond $6000 \mathrm{~m}^{2} / \mathrm{g}$ ) and large density of active sites ${ }^{23,24}$. During the last decade, extensive research attempts have been devoted for the preparation of various MOFs and investigations of their application in different fields of science such as, energy storages, biomedical technology, environmental pollution, sensing platforms and catalysis ${ }^{25-31}$. Recently, due to the aforementioned properties, these great porous materials have been attracted chemist's attention in the term of heterogeneous catalysis ${ }^{32-34}$.

Copper azide-alkyne (CuAAC) cycloaddition reaction is a famous 1,3-dipolar cycloaddition in which the 1,2,3-triazole derivatives are produced with high selectivity ${ }^{35-38}$. The synthesis of these 5-membered compounds is very interesting in organic synthesis and this reaction is the core of many synthetic routes for total synthesis ${ }^{39,40}$. During the past decades, this reaction has been investigated with different kinds of Cu catalysts such as $\mathrm{CuI}^{41}$, $\mathrm{Cu}(\mathrm{OAc})_{2}{ }^{42}, \mathrm{CuO}^{43}, \mathrm{CuCl}_{2} \cdot 2 \mathrm{H}_{2} \mathrm{O}^{44}$ and $\mathrm{CuSO}_{4} \cdot 5 \mathrm{H}_{2} \mathrm{O}^{45}, \mathrm{Fe}_{3} \mathrm{O}_{4} \mathrm{NPs}$ supported $\mathrm{Cu}(\mathrm{II})-\beta$-cyclodextrin ${ }^{46}, \mathrm{Fe}_{3} \mathrm{O}_{4} @$ $\mathrm{SiO}_{2}$ picolinimidoamide- $\mathrm{Cu}$ (II) complex ${ }^{47}, \mathrm{Cu}(\mathrm{II})$ porphyrin graphene oxide ${ }^{48}$, and $\mathrm{Cu}(\mathrm{II})$-supported graphene quantum dots ${ }^{49}$. However, most of the abovementioned $\mathrm{Cu}$ catalysts suffered from some sever problems like expensive catalyst preparation methods, using the toxic solvents and reagents, and more importantly difficult catalyst separation approaches. Therefore, present the new and applicable $\mathrm{Cu}$ catalyst is a pressing need in organic synthesis and highly recommended for the synthesis of 1,2,3-triazole derivatives.

Hence, in this research and in continuation of research programs to develop the organic synthesis and catalysis $^{50-53}$, a new magnetic MOF catalyst has been prepared with core-shell structure. So, initially the $\mathrm{Fe}_{3} \mathrm{O}_{4}$ MNPs have been prepared in the nano dimensions and then, they have been coated with MOFs with $\mathrm{Cu}$ as inorganic nodes and 1,3,5-benzenetricarboxylic acid as organic linkers $\left(\left[\mathrm{Cu}_{3}(\mathrm{btc})_{2}\right]\right.$ btc $=$ benzene-1,3,5-tricarboxylic 

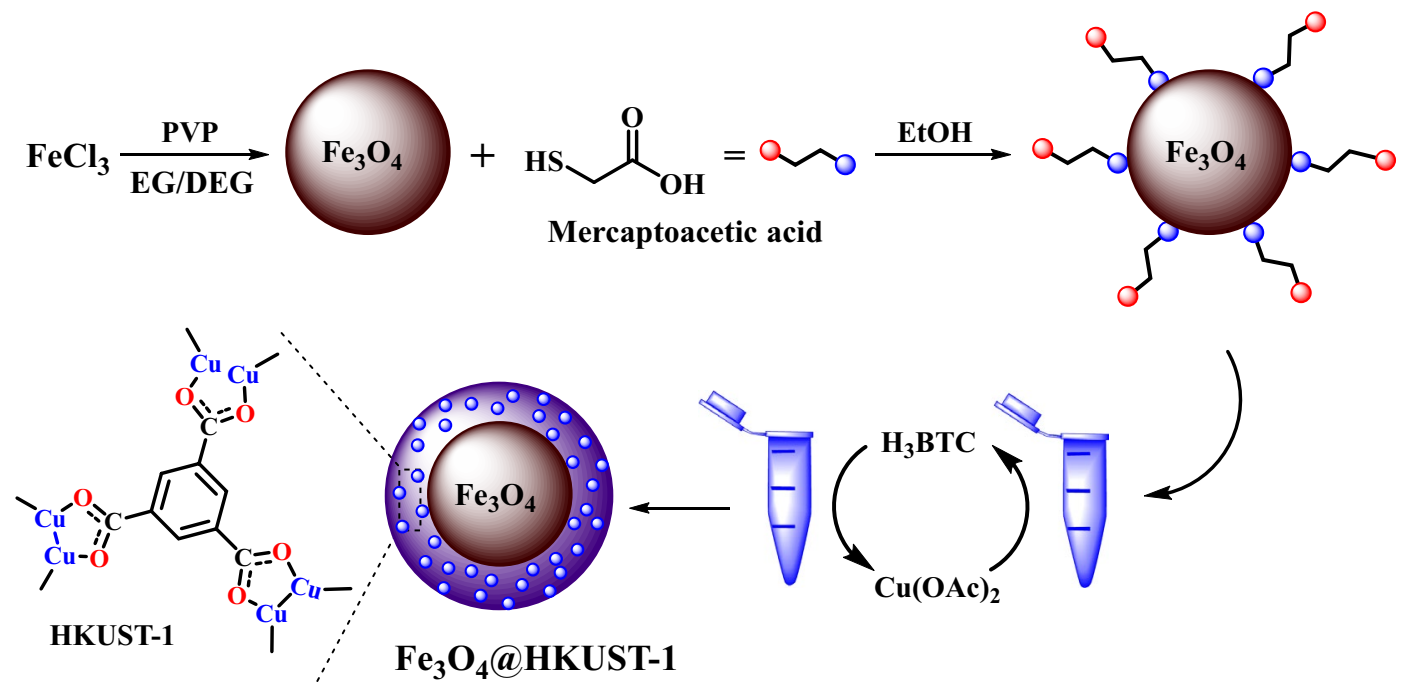

Figure 1. Synthesis of catalyst $\left(\mathrm{Fe}_{3} \mathrm{O}_{4} @ H K U S T-1\right)$.

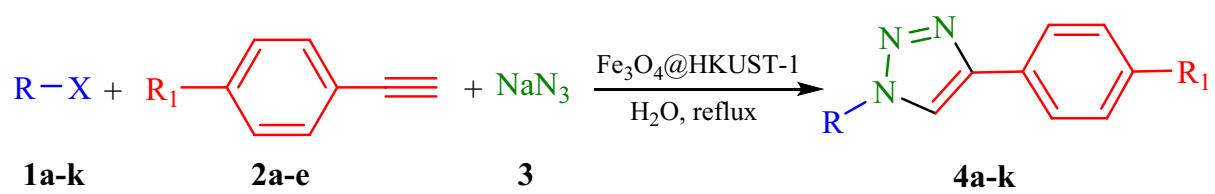

Figure 2. Synthesis of 1,2,3-triazole derivatives in presence of catalyst $\left(\mathrm{Fe}_{3} \mathrm{O}_{4} @ H K U S T-1\right)$.

acid, HKUST-1 $)^{54}$ (Fig. 1). This easy prepared nanocatalyst can catalyze the synthesis of 1,2,3-triazole derivatives with good to excellent yields and mild reaction conditions (Fig. 2). It is prime importance to note that, to the best of our knowledge, there are no publications for the synthesis 1,2,3-triazole derivatives with the use of magnetic MOFs based on $\mathrm{Cu}$ catalyst.

\section{Results and discussion}

In this research, a magnetic metal organic framework with core-shell structure based on HKUST-1 MOF has been developed as an efficient and recyclable catalyst (Fig. 1). Hence, firstly, the $\mathrm{Fe}_{3} \mathrm{O}_{4} \mathrm{MNPs}$ have been prepared by using $\mathrm{FeCl}_{3}$ and hydrothermal process ${ }^{55}$, and then, the surface of these MNPs has been modified by mercaptoacetic acid and finally, these modified MNPs have been coated with HKUST-1 MOF by a versatile layer-by-layer assembly method and using copper acetate and 1,3,5-benzenetricarboxylic acid $\left(\mathrm{H}_{3} \text {-BTC) (Fig. } 1\right)^{56}$. The catalyst structure was characterized with different techniques including, TEM, SEM, TEM mapping, SEM mapping, EDX, TGA, PXRD, VSM, and ICP.

At first, all steps for the preparation of magnetic core-shell $\left(\mathrm{Fe}_{3} \mathrm{O}_{4} @ \mathrm{HKUST}-1\right)$ catalyst have been studied by the FT-IR spectroscopy (Fig. 3). In the first spectrum related to $\mathrm{Fe}_{3} \mathrm{O}_{4}$ MNPs (Fig. 3a), there are two distinct sharp peaks at 3414 and $569 \mathrm{~cm}^{-1}$ that are attributed to the $\mathrm{O}-\mathrm{H}$ stretching bands of the hydroxyl functional groups on the surface of MNPs and Fe-O bonds into the structure of MNPs, respectively ${ }^{55}$. In the next spectrum correspond to modified MNPs with mercaptoacetic acid (Fig. 3b), there are not any significant differences between this spectrum with previous one and approximately all peaks are retained with moderate shifts. But in the last spectrum of $\mathrm{Fe}_{3} \mathrm{O}_{4} @ H K U S T-1$ (Fig. 3c), there are some new peaks including two characteristic peaks at 1615 and $1554 \mathrm{~cm}^{-1}$ that can be assigned to the asymmetric stretching vibrations of - COO- and two sharp peaks at 1434 and $1371 \mathrm{~cm}^{-1}$ can be ascribed to the symmetric vibrations of $-\mathrm{COO}^{-56,57}$.

SEM and TEM techniques are the important analysis for evaluation of core-shell structures and investigation of morphology and size of NPs. Thereby, SEM and TEM images of bare $\mathrm{Fe}_{3} \mathrm{O}_{4}$ and core-shell $\mathrm{Fe}_{3} \mathrm{O}_{4} @ H K U S T-1$ MNPs (Final catalyst) have been provided (Fig. 4). As it is evident from SEM images (Fig. 4a and b), the morphology of MNPs is spherical and it has been somewhat changed after coating process (Fig. 4b). Also, the size of bare $\mathrm{Fe}_{3} \mathrm{O}_{4}$ and core-shell $\mathrm{Fe}_{3} \mathrm{O}_{4} @ H K U S T-1 \mathrm{MNPs}$ is below $50 \mathrm{~nm}$. Besides, the core-shell structures are confirmed properly with TEM images (Fig. $4 \mathrm{~d})^{19}$. Also, the excellent analysis to approve the core-shell structures and elemental analysis is TEM mapping (Fig. 5). This figure obviously showed the core-shell structures of magnetic MOF with all elements including the iron and oxygen for core moieties and sulfur, carbon, and cupper related to the shell parts. As we can see in this image, the morphology of core parts $(\mathrm{Fe}, \mathrm{O})$ is changed after coating with $\operatorname{MOF}(\mathrm{S}, \mathrm{C}, \mathrm{Cu})$. Another great analysis to confirm the structure is SEM mapping. As shown in Fig. 6, all elements of catalyst including $\mathrm{Fe}, \mathrm{O}, \mathrm{S}, \mathrm{C}$ and $\mathrm{Cu}$ are existed in this figure. This figure showed that in addition to iron and 


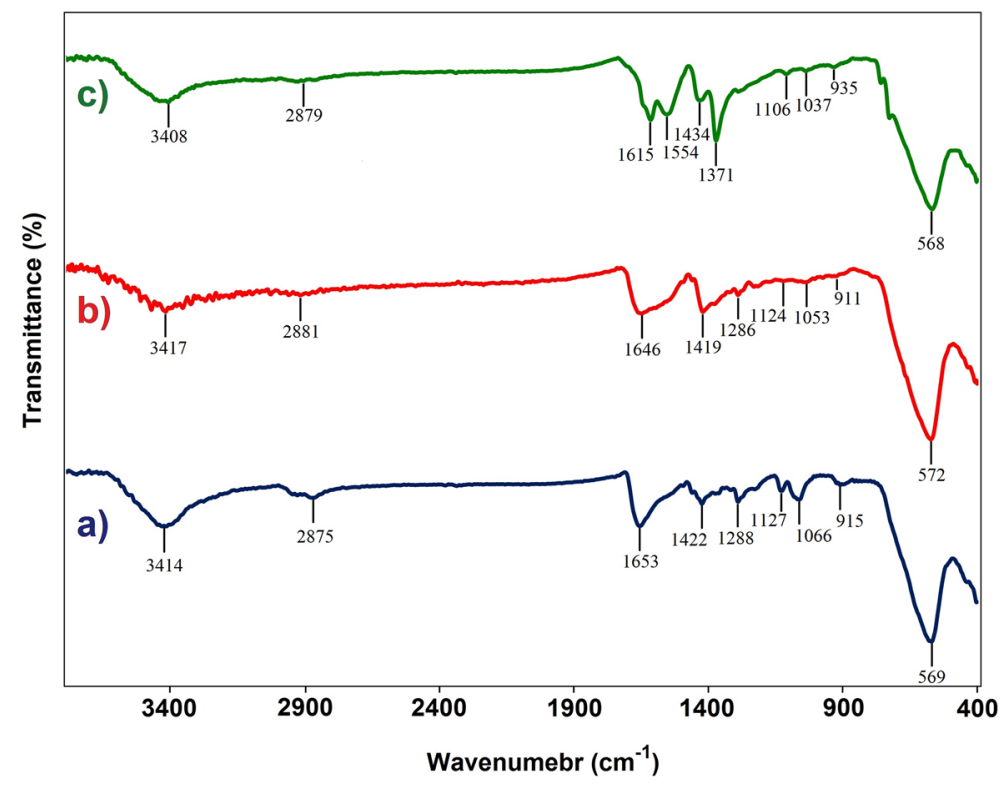

Figure 3. FT-IR spectra of (a) $\mathrm{Fe}_{3} \mathrm{O}_{4}$ (b) $\mathrm{Fe}_{3} \mathrm{O}_{4}$-mercaptoacetic acid and (c) of $\mathrm{Fe}_{3} \mathrm{O}_{4} @ H K U S T-1$.

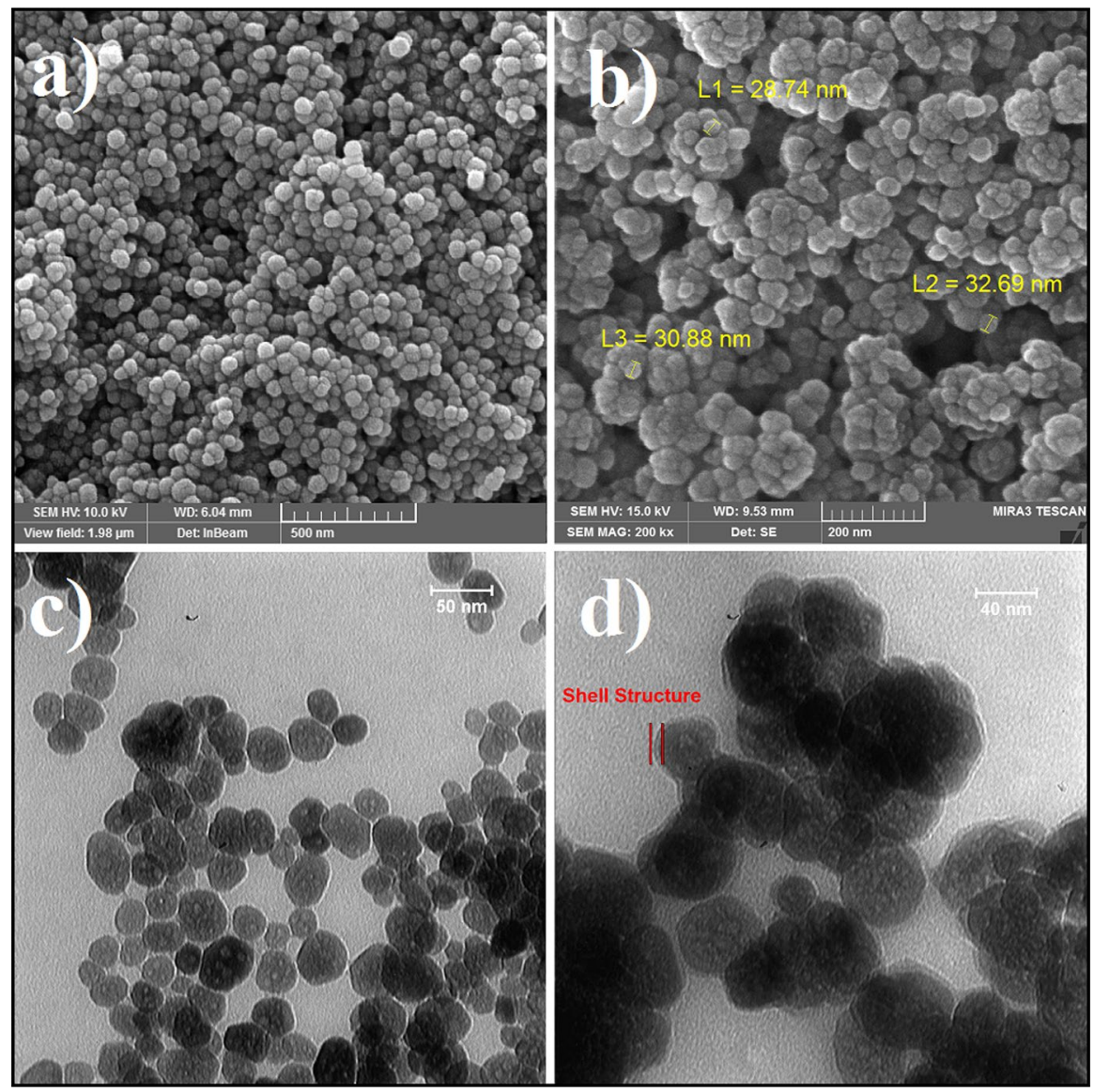

Figure 4. SEM (a) and TEM (c) images of $\mathrm{Fe}_{3} \mathrm{O}_{4}$ and SEM (b) and TEM (d) images of $\mathrm{Fe}_{3} \mathrm{O}_{4} @ H K U S T-1$. 


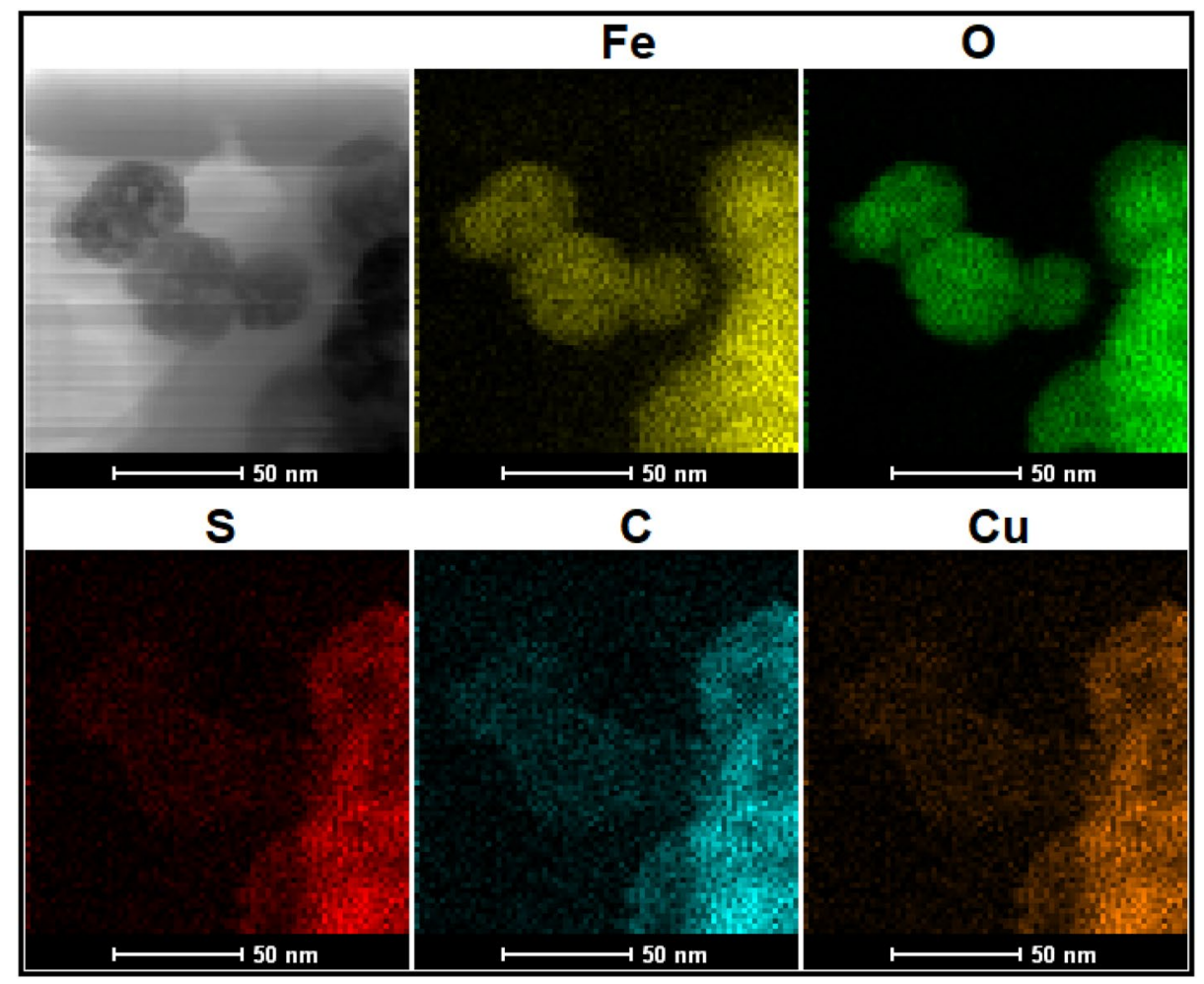

Figure 5. TEM mapping of $\mathrm{Fe}_{3} \mathrm{O}_{4} @ H K U S T-1$.

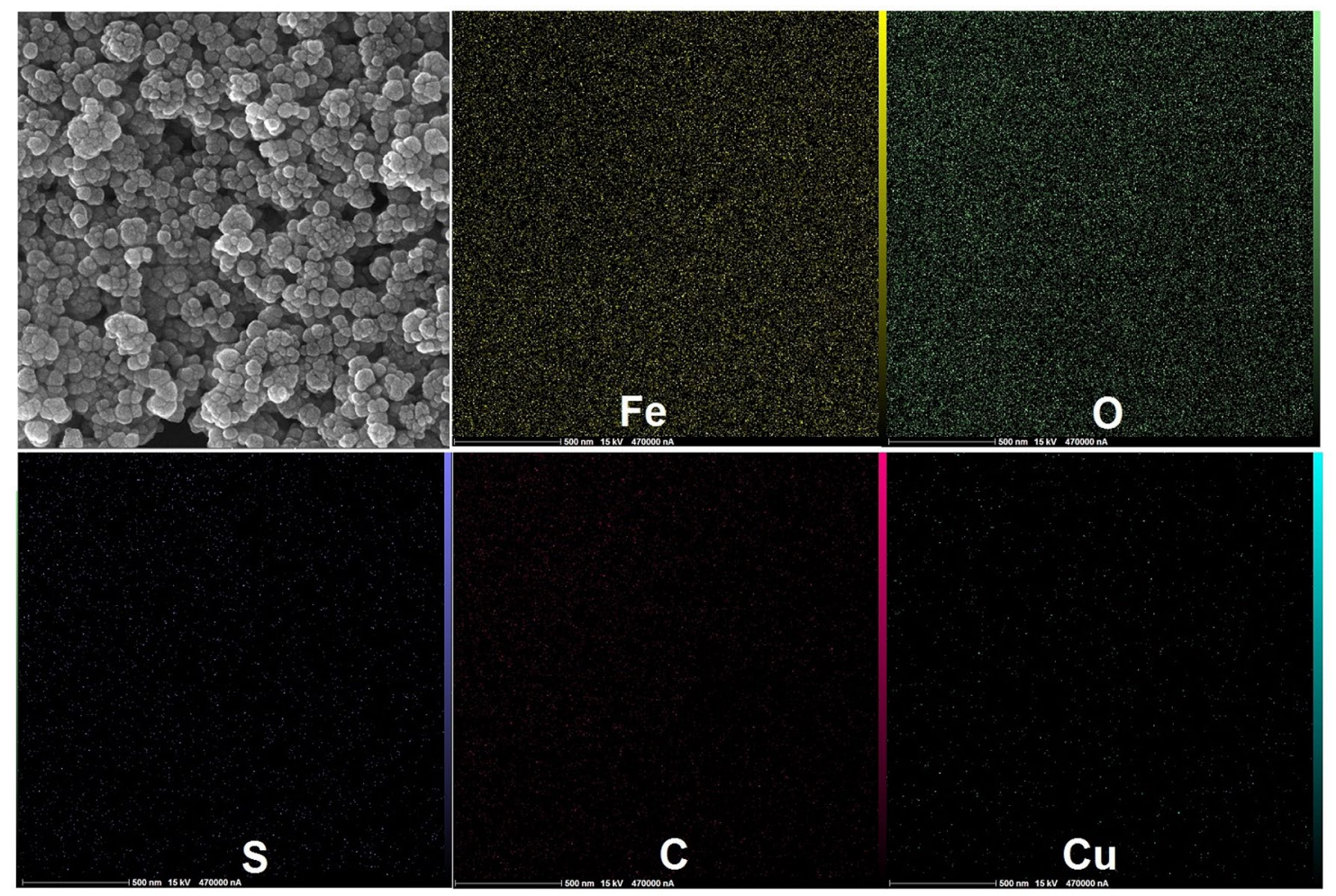

Figure 6. SEM mapping of $\mathrm{Fe}_{3} \mathrm{O}_{4} @ H K U S T-1$. 

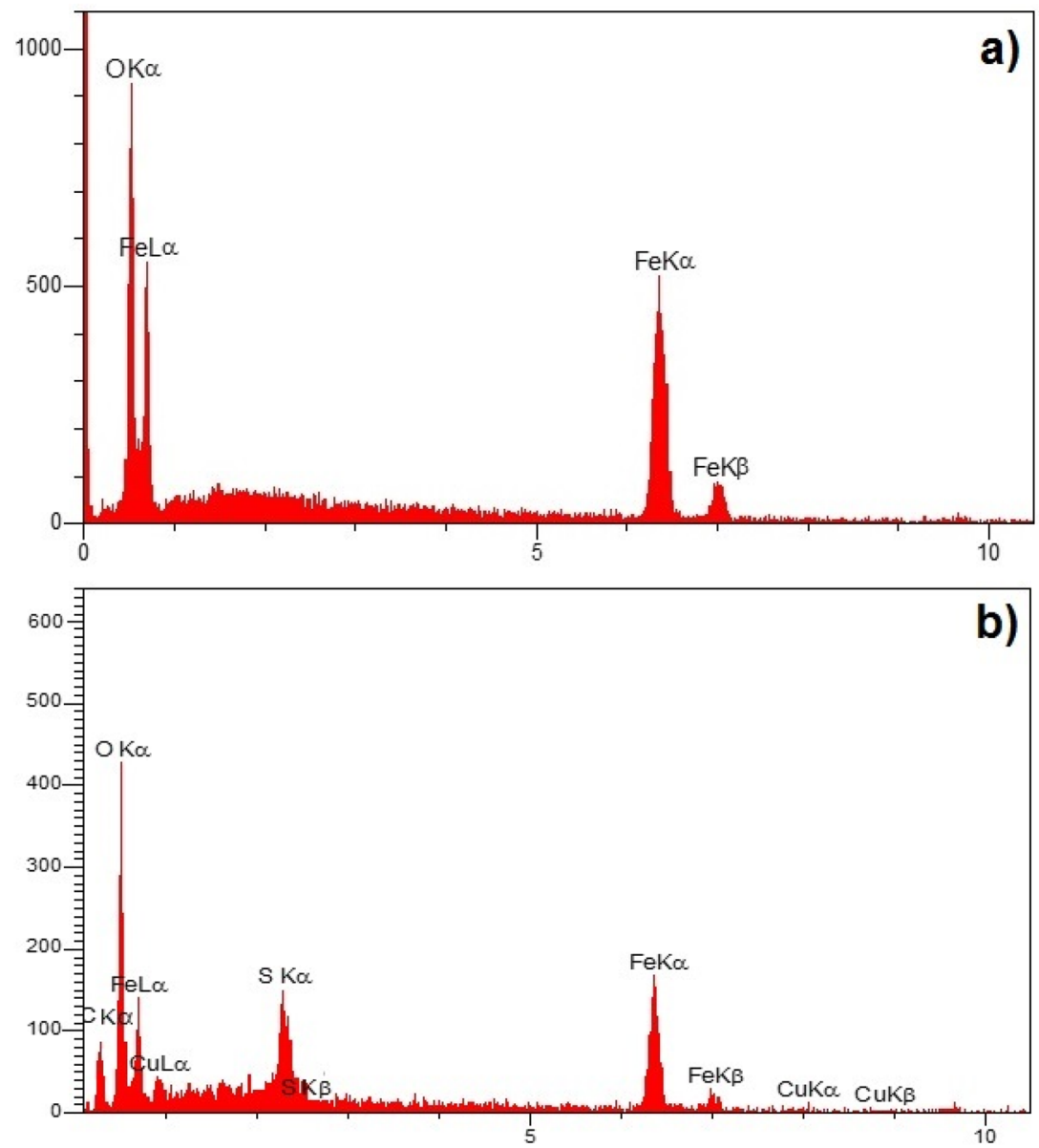

Figure 7. EDX patterns of (a) $\mathrm{Fe}_{3} \mathrm{O}_{4}$ and (b) $\mathrm{Fe}_{3} \mathrm{O}_{4} @ H K U S T-1$.

oxygen that are the elements of $\mathrm{Fe}_{3} \mathrm{O}_{4}$ MNPs, sulfur and particularly carbon, and copper are existed that are the main elements of shell structures. These outcomes approve the successful formation of core-shell structures.

EDX analysis was also performed to study again the elemental analysis. So, this analysis was investigated for both bare $\mathrm{Fe}_{3} \mathrm{O}_{4}$ and core-shell $\mathrm{Fe}_{3} \mathrm{O}_{4} @$ @KUST-1 MNPs (Fig. 7). As can be seen in the first pattern (Fig. 7a) correspond to $\mathrm{Fe}_{3} \mathrm{O}_{4}$ MNPs, the iron and oxygen are presented, while in the second pattern (Fig. 7b), in addition to Fe and $\mathrm{O}$, some new elements related to shell structures including sulfur, carbon and more importantly copper are observed.

The powder X-ray diffraction (PXRD) analysis was studied for both bare $\mathrm{Fe}_{3} \mathrm{O}_{4}$ and core-shell $\mathrm{Fe}_{3} \mathrm{O}_{4} @$ HKUST-1 MNPs (Fig. 8). The PXRD pattern of $\mathrm{Fe}_{3} \mathrm{O}_{4}$ MNPs (Fig. 8a) shows the crystalline phase character-

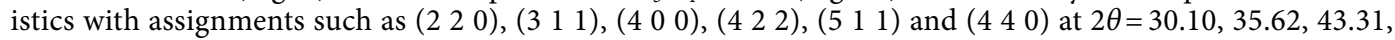
53.30, 57.11 and 62.10 (JCPDS card No. 19-0629) ${ }^{58}$. In the second PXRD pattern of $\mathrm{Fe}_{3} \mathrm{O}_{4} @ H K U S T-1$ MNPs (Fig. 8b), in addition to $\mathrm{Fe}_{3} \mathrm{O}_{4} \mathrm{MNPs}$ peaks, some new peaks are observed between ranges of $2 \Theta=5$ to 30 which are attributed to the HKUST-1 MOF shell structures ${ }^{57}$. These observations confirm the successful formation of magnetic MOF structures.

It is known that the TGA analysis is a significant factor to confirm the core-shell structures and evaluate the thermal stability of the samples (Fig. 9). As shown in Fig. 9a, the $\mathrm{Fe}_{3} \mathrm{O}_{4}$ MNPs have high thermal stability due to the iron oxide structures and only $9.958 \%$ of sample's weight has been decreased after increase the temperature to $500{ }^{\circ} \mathrm{C}$. It can be attributed to the decomposition of hydroxyl functional groups on the surface of MNPs or remove of some waters or organic solvents remained in the sample. Interestingly, the TGA graph of $\mathrm{Fe}_{3} \mathrm{O}_{4} @ \mathrm{HKUST}-1$ MNPs showed more reduction in the weight (about $22.176 \%$, Fig. 9b). The difference between this weigh loss with previous one is about $12 \%$ that can be assigned to the decomposition of shell structures ${ }^{59}$.

Figure 10 shows magnetic properties of the $\mathrm{Fe}_{3} \mathrm{O}_{4}$ and core-shell MNP structures at room temperature in the range of $+15,000$ to $-15,000$ Oe. Thus, the VSM plot of $\mathrm{Fe}_{3} \mathrm{O}_{4} \mathrm{MNPs}$ exhibited the superparamagnetic properties with high saturation magnetization about $85 \mathrm{emu} \mathrm{g}^{-1}$ (Fig. 10, black graph). It is noteworthy, this magnetic property was reduced to about $65 \mathrm{emu} \mathrm{g}^{-1}$ after coating the MNPs with MOF shell structures (Fig. 10, red graph $)^{60}$. These outcomes approve the successful synthesis of catalyst and it is in agreement with TEM, XRD and TGA results.

It is essential to obtain the amount of copper in the samples. Thereby, its amount in both fresh and reused catalyst (after five times reuse) has been estimated by ICP analysis. According to the ICP results, the weight 


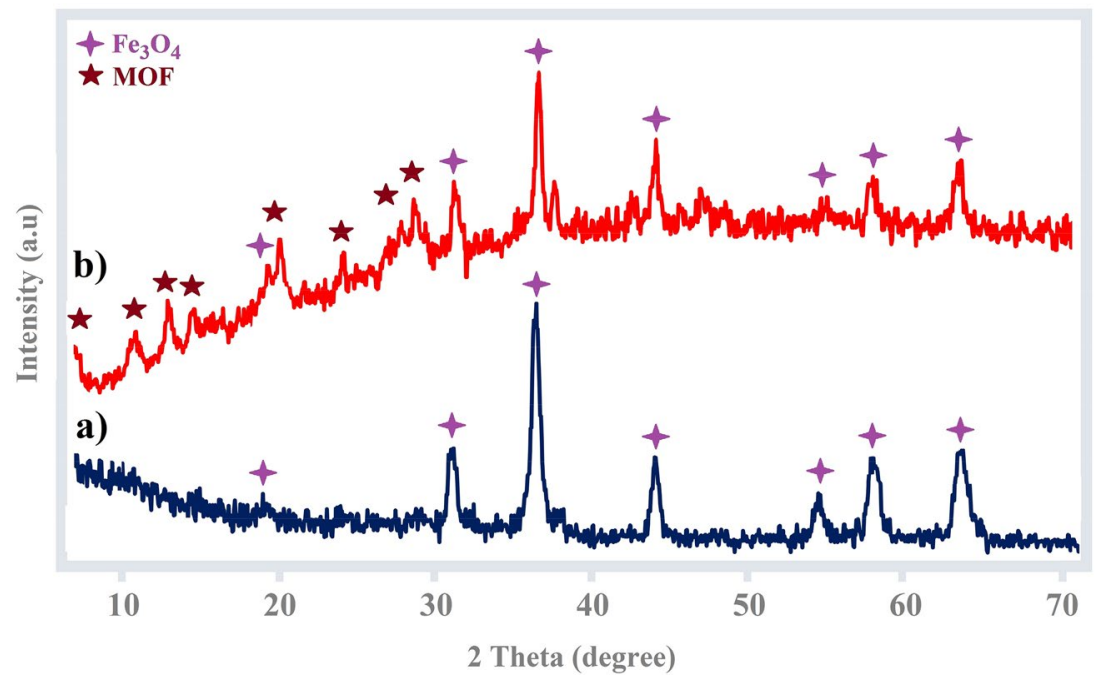

Figure 8. XRD pattern of (a) $\mathrm{Fe}_{3} \mathrm{O}_{4}$ and (b) $\mathrm{Fe}_{3} \mathrm{O}_{4} @ H K U S T-1$.

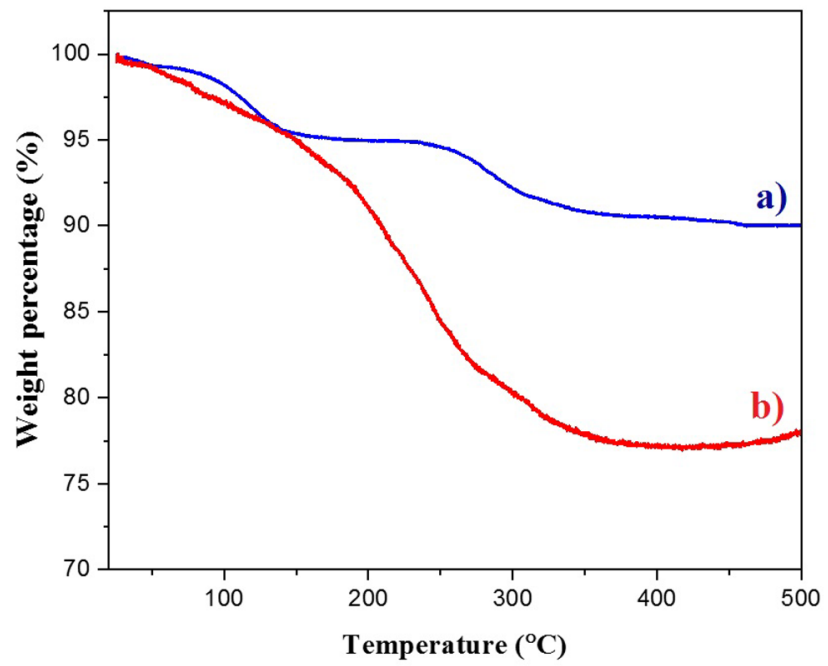

Figure 9. TGA graph of catalyst (a) $\mathrm{Fe}_{3} \mathrm{O}_{4}$ and (b) $\mathrm{Fe}_{3} \mathrm{O}_{4} @ H K U S T-1$.

percentage of $\mathrm{Cu}$ in the fresh and reused catalyst were 3.512 and $3.497 \mathrm{wt} \%$, respectively. This analysis strongly confirmed the presence of copper in MOF structures (in accordance with EDX and SEM mapping observations) and also shows the leaching of $\mathrm{Cu}$ and shell structures is negligible amount that can be ignored.

After complete characterization the catalyst structure, the catalyst efficiency has been investigated for the synthesis of 1,2,3-triazole derivatives from the three component condensation reaction of different alkyl halides, various phenylacetylene and sodium azide. To this end, initially, the reaction of benzyl bromide, phenylacetylene and sodium azide has been selected as a model reaction by taking into account several important factors such as amount of catalyst, effect of solvent and temperature (Table 1). Hence, at first step, the reaction was carried out without the catalyst under the solvent-free conditions or water as a green solvent (entries 1 and 2). As expected, with solvent-free conditions and without the catalyst, the reaction did not have any desirable product (entry 1 ) and the amount of product was trace in water (entry 2). With adding the catalyst to the reaction mixture, the yield of the reaction has been increased gradually (entries 3-6). The best amount of catalyst was obtained $30 \mathrm{mg}(1.8 \mathrm{~mol} \%)$ (entry 5). After find the optimum amount of the catalyst, the reaction was examined in the presence of different solvents that such as THF, DMF, $\mathrm{MeCN}, \mathrm{MeOH}, \mathrm{EtOH}, \mathrm{H}_{2} \mathrm{O}$ and solvent-free conditions (entries 7-12). The highest and lowest amount of 1,2,3-triazole compound were obtained in the presence of water and solvent-free condition, respectively (entries 5 and 12). The last step was study the effect of temperature on model reaction (entries 13-15). Therefore, the model reaction was carried out at different temperatures like 25, 50,100 and $120^{\circ} \mathrm{C}$. The best temperature was $100^{\circ} \mathrm{C}$ (reflux condition) and lower and higher temperature was not satisfying. So, the best condition was the using of water as a green solvent under reflux condition and $30 \mathrm{mg}$ (1.8 mol\%) of catalyst (entry 5). 


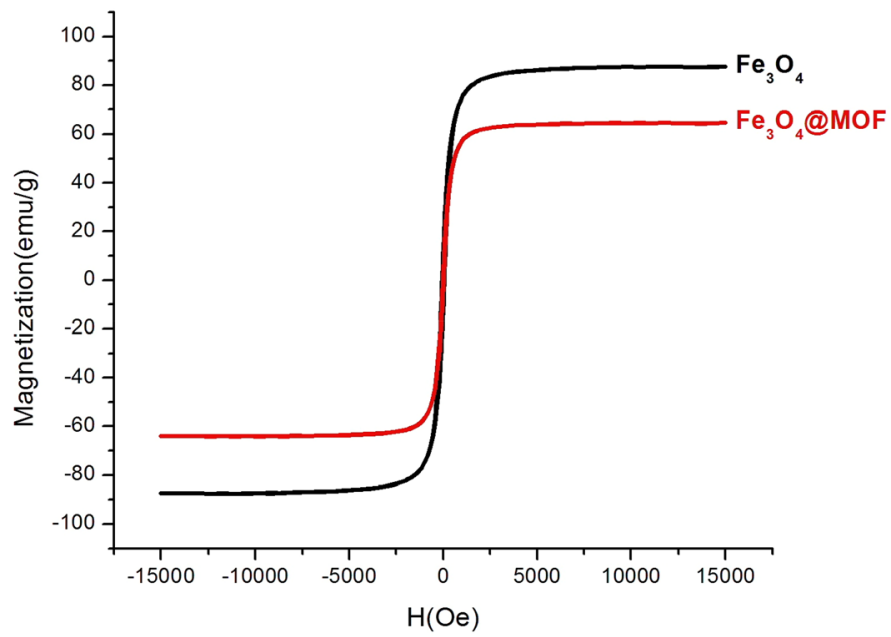

Figure 10. VSM graphs of (a) $\mathrm{Fe}_{3} \mathrm{O}_{4}$ and (b) $\mathrm{Fe}_{3} \mathrm{O}_{4} @ H K U S T-1$.

\begin{tabular}{|l|l|l|l|l|l|l|}
\hline Entry & Conditions & Catalyst $(\mathbf{m g}, \mathbf{m o l} \%)$ & Temp. $\left({ }^{\circ} \mathbf{C}\right)$ & Time $(\mathbf{m i n})$ & TON/TOF & ${\text { Yield }(\%)^{\mathbf{c}}}^{\mathbf{b}}$ \\
\hline 1 & Solvent-free & - & rt & 360 & - & - \\
\hline 2 & $\mathrm{H}_{2} \mathrm{O}$ & - & Reflux & 300 & - & Trace \\
\hline 3 & $\mathrm{H}_{2} \mathrm{O}$ & $10,0.6$ & Reflux & 180 & $71.7 / 0.40$ & 43 \\
\hline 4 & $\mathrm{H}_{2} \mathrm{O}$ & $20,1.2$ & Reflux & 180 & $56.7 / 0.31$ & 68 \\
\hline 5 & $\mathrm{H}_{2} \mathrm{O}$ & $30,1.8$ & Reflux & 120 & $51.1 / 0.43$ & 92 \\
\hline 6 & $\mathrm{H}_{2} \mathrm{O}$ & $40,2.4$ & Reflux & 120 & $37.5 / 0.31$ & 90 \\
\hline 7 & $\mathrm{THF}$ & $30,1.8$ & Reflux & 130 & $18.9 / 0.14$ & 34 \\
\hline 8 & $\mathrm{DMF}$ & $30,1.8$ & 100 & 130 & $23.3 / 0.18$ & 50 \\
\hline 9 & $\mathrm{MeCN}$ & $30,1.8$ & Reflux & 130 & $24.4 / 0.19$ & 44 \\
\hline 10 & $\mathrm{MeOH}$ & $30,1.8$ & Reflux & 130 & $30.5 / 0.23$ & 63 \\
\hline 11 & $\mathrm{EtOH}$ & $30,1.8$ & Reflux & 130 & $33.9 / 0.26$ & 70 \\
\hline 12 & $\mathrm{Solvent}$ free & $30,1.8$ & 100 & 130 & - & Trace \\
\hline 13 & $\mathrm{H}_{2} \mathrm{O}$ & $30,1.8$ & r.t & 130 & - & Trace \\
\hline 14 & $\mathrm{H}_{2} \mathrm{O}$ & $30,1.8$ & 50 & 130 & $28.3 / 0.22$ & 51 \\
\hline 15 & $\mathrm{H}_{2} \mathrm{O}$ & $30,1.8$ & 120 & 130 & $50.0 / 0.38$ & 90 \\
\hline 16 & $\mathrm{H}_{2} \mathrm{O}^{\mathrm{d}}$ & $30,1.8$ & Reflux & 120 & $48.3 / 0.40$ & 87 \\
\hline 17 & $\mathrm{H}_{2} \mathrm{O}^{\mathrm{e}}$ & $30,1.8$ & Reflux & 120 & $46.1 / 0.38$ & 83 \\
\hline 18 & $\mathrm{H}_{2} \mathrm{O}^{\mathrm{f}}$ & $30,1.8$ & Reflux & 120 & $44.4 / 0.37$ & 80 \\
\hline & & & &
\end{tabular}

Table 1. Screening of the reaction conditions for the synthesis of $4 a^{a} \cdot{ }^{a}$ Reaction condition: Benzyl bromide $(1 \mathrm{mmol})$, phenylacetylene $(1 \mathrm{mmol})$, sodium azide $(1.2 \mathrm{mmol}) .{ }^{\mathrm{b}}$ Turn Over Number (yield of the reaction/ mol\%)/Turn Over Frequency (TON/time of the reaction). ${ }^{c}$ Based on isolated yield. ${ }^{\mathrm{d}}$ In the presence of HKUST-1. ${ }^{\mathrm{e}}$ In the presence of $\mathrm{Cu}(\mathrm{OAc})_{2} .{ }^{\mathrm{f}} \mathrm{In}$ the presence of $\mathrm{CuCl}_{2}$.

In the second step and after finding the optimized reaction condition, the generality of this research was investigated in the reaction of different alkyl and benzyl halides with sodium azide and various phenyl acetylene and also in the attendance of $30 \mathrm{mg}(1.8 \mathrm{~mol} \%)$ of $\mathrm{Fe}_{3} \mathrm{O}_{4} @ H K U S T-1$ catalyst and water as a green solvent at $100{ }^{\circ} \mathrm{C}$ (Table 2). It is worth mentioning that, benzyl halides (entries 1-8) reacted better compared to alkyl halides (entries 9-11) on the basis of yield of the reaction and gave the product with highest amounts of yield. On the other hand, the phenylacetylene derivatives with no substituent (entries 1, 5, 6, and 8) or with electronwithdrawing group (entry 13) have better yield of the reaction compared to electron-donating groups (entries 12, 14 and 15). After that, in order to investigate the catalyst efficiency, the effects of bare MOF (HKUST-1) without the core $\left(\mathrm{Fe}_{3} \mathrm{O}_{4}\right)$ (entry 16) and some $\mathrm{Cu}$ salts like $\mathrm{Cu}(\mathrm{OAc})_{2}$ and $\mathrm{CuCl}_{2}$ (entries 17 and 18) have been tested in the model reaction under optimized conditions. As is evident, the yields of the reaction in presence of HKUST-1, copper acetate and copper chloride were 87,83 and $80 \%$ respectively that they are a little bit lower than $\mathrm{Fe}_{3} \mathrm{O}_{4} @$ HKUST-1 which can be attributed to the nano structures of the final catalyst.

According to the literature ${ }^{61,62}$, a suggested reaction mechanism for the 1,3-dipolar cycloaddition reaction in the attendance of $\mathrm{Fe}_{3} \mathrm{O}_{4} @$ HKUST-1 catalyst was proposed (Fig. 11). As mentioned before in the shell structure, the copper (II) was existed that it can be acted as a Lewis acid and catalyzed the synthesis of 1,2,3-triazole 


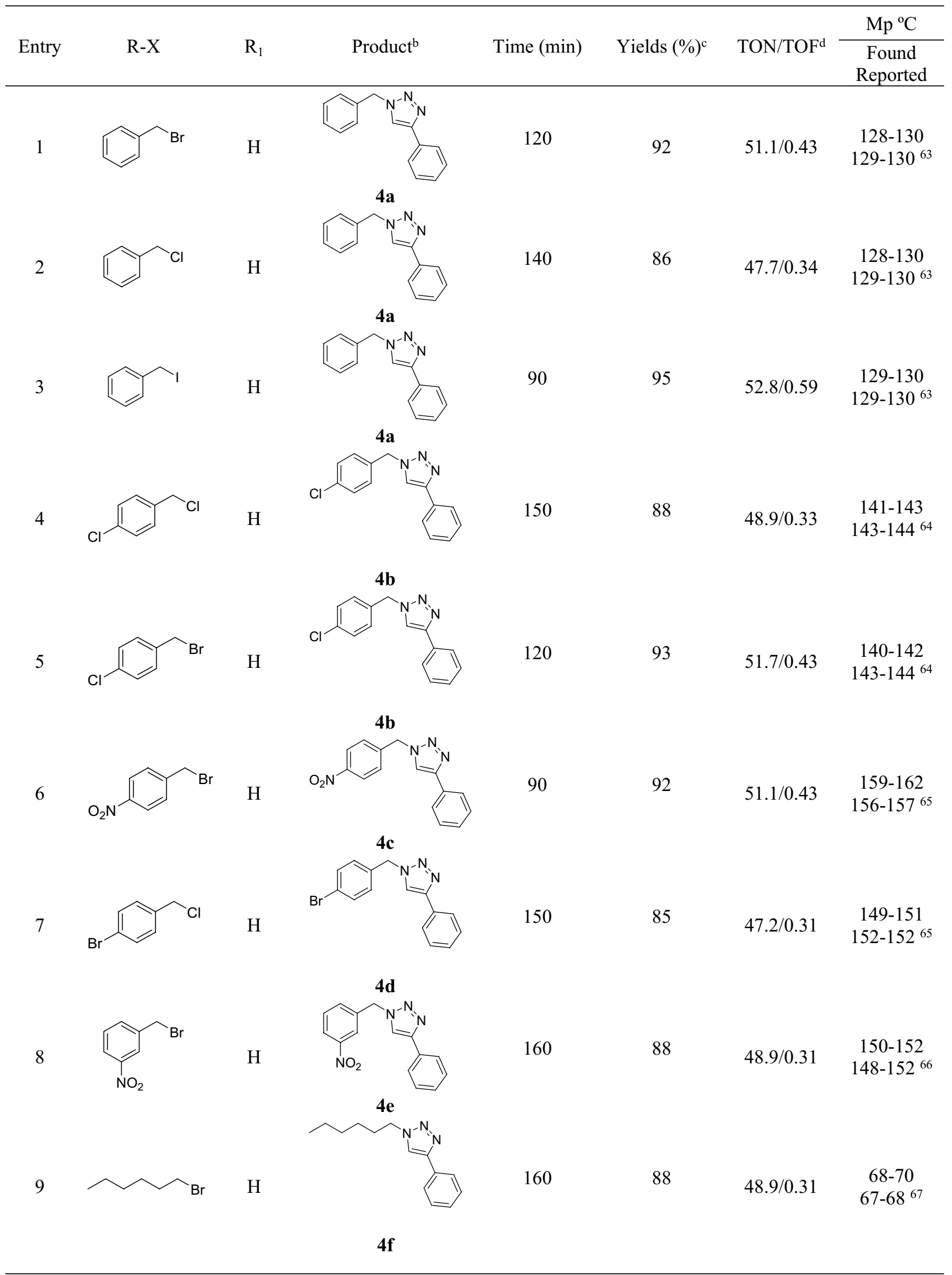

Table 2. (continued) 


\begin{tabular}{|c|c|c|c|c|c|c|c|}
\hline \multirow[b]{2}{*}{ Entry } & \multirow[b]{2}{*}{$\mathrm{R}-\mathrm{X}$} & \multirow[b]{2}{*}{$\mathrm{R}_{1}$} & \multirow[b]{2}{*}{ Product $^{\mathrm{b}}$} & \multirow[b]{2}{*}{ Time (min) } & \multirow[b]{2}{*}{ Yields $(\%)^{\mathrm{c}}$} & \multirow[b]{2}{*}{$\mathrm{TON} / \mathrm{TOF}^{\mathrm{d}}$} & $\mathrm{Mp}{ }^{\circ} \mathrm{C}$ \\
\hline & & & & & & & $\begin{array}{c}\text { Found } \\
\text { Reported }\end{array}$ \\
\hline 10 & & $\mathrm{H}$ & & 180 & 80 & $44.4 / 0.25$ & $\begin{array}{c}69-71 \\
67-68^{67}\end{array}$ \\
\hline 11 & & $\mathrm{H}$ & & 150 & 85 & $47.2 / 0.31$ & $\begin{array}{c}79-82 \\
78-79^{64}\end{array}$ \\
\hline 12 & & 4-Me & & 180 & 89 & $49.4 / 0.27$ & $\begin{array}{c}142-145 \\
142-146^{68}\end{array}$ \\
\hline 13 & & $4-\mathrm{Br}$ & & 150 & 91 & $50.5 / 0.34$ & $\begin{array}{c}142-144 \\
143-14568\end{array}$ \\
\hline 14 & & 4-MeO & & 180 & 86 & $48.2 / 0.40$ & $\begin{array}{c}138-140 \\
139-141^{68}\end{array}$ \\
\hline 15 & & 4-t-but & & 180 & 84 & $46.7 / 0.26$ & $\begin{array}{c}111-113 \\
112-114^{68}\end{array}$ \\
\hline & & & $4 k$ & & & & \\
\hline
\end{tabular}

Table 2. Synthesis of 1,2,3-triazole derivetives using $\mathrm{Fe}_{3} \mathrm{O}_{4} @ H K U S T-1$ nanocatalyst ${ }^{\mathrm{a}}$. ${ }^{\mathrm{a}}$ Reaction condition: Benzyl/alkyl halide $(1.0 \mathrm{mmol})$, phenylacetylene derivatives $(1.0 \mathrm{mmol})$, sodium azide $(1.2 \mathrm{mmol})$, catalyst (30 mg, $1.8 \mathrm{~mol} \%$ ) and $\mathrm{H}_{2} \mathrm{O}$ at $100{ }^{\circ} \mathrm{C}$. ${ }^{\mathrm{b}}$ All the products were charchetrized by ${ }^{1} \mathrm{H} \mathrm{NMR},{ }^{13} \mathrm{C}$ NMR and FT-IR. ${ }^{\mathrm{c}}$ Isolated Yields. ${ }^{\mathrm{d}}$ Turn Over Number (yield of the reaction/mol\%)/Turn Over Frequency (TON/time of the reaction).

derivatives properly. On this basis, in the first step, the phenyl acetylene can be coordinated to $\mathrm{Cu}$ centers in the MOF structures and the $\mathrm{Cu}$-alkylidine intermediate is formed. Next, the alkyl or benzyl halide as an electrophile can react with sodium azide as nucleophile and the alkyl or benzyl azide are produced. Afterwards, it attacks with previous formed $\mathrm{Cu}$ intermediate and finally, after simple intramolecular cyclization, the final product is generated.

Our catalyst exhibited high catalytic stability in repeated model reaction. On this basis, after finalization the model reaction, the $\mathrm{Fe}_{3} \mathrm{O}_{4} @ \mathrm{HKUST}-1$ catalyst was separated from the reaction mixture by an external magnet and washed several times with DMF and acetone, dried in vacuum oven at $50{ }^{\circ} \mathrm{C}$ for $12 \mathrm{~h}$ and reused in the next model reaction. It can catalyze the synthesis of 1,2,3-triazole derivatives with high isolated yield and after five time reusing the catalyst, the yield of the reaction decreased very low that it can be ignored (Fig. 12). These observations showed the structure of catalyst and especially shell structures stay without change during the reaction and probably no leaching of $\mathrm{Cu}$ and MOF materials has been occurred during the reaction.

Hot filtration test was also performed to scrutiny the stability of catalyst. In this regard, the model reaction of benzyl bromide $(1.0 \mathrm{mmol})$, sodium azide $(1.2 \mathrm{mmol})$ and phenyacetylene $(1.0 \mathrm{mmol})$ has been carried out in the presence of optimum amount of catalyst $(1.8 \mathrm{~mol} \%)$ and water under reflux condition for $60 \mathrm{~min}$. After 


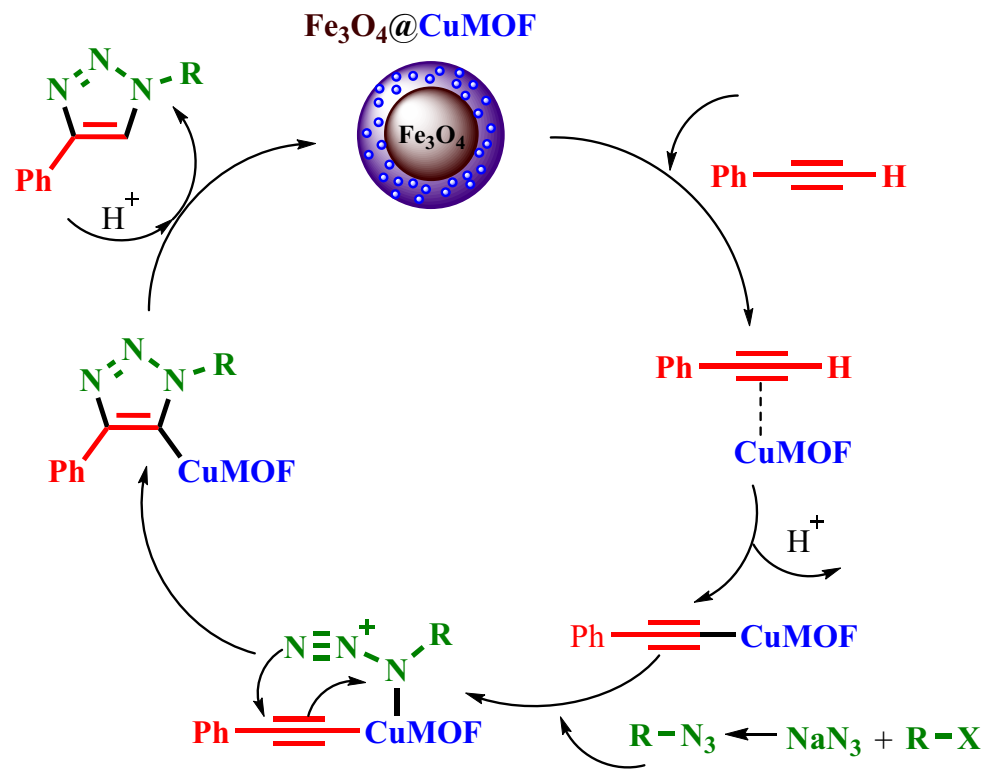

Figure 11. The proposed mechanism for the synthesis of 1,2,3-triazoles in the presence of $\mathrm{Fe}_{3} \mathrm{O}_{4} @ \mathrm{HKUST}-1 \mathrm{Cu}$ catalyst.

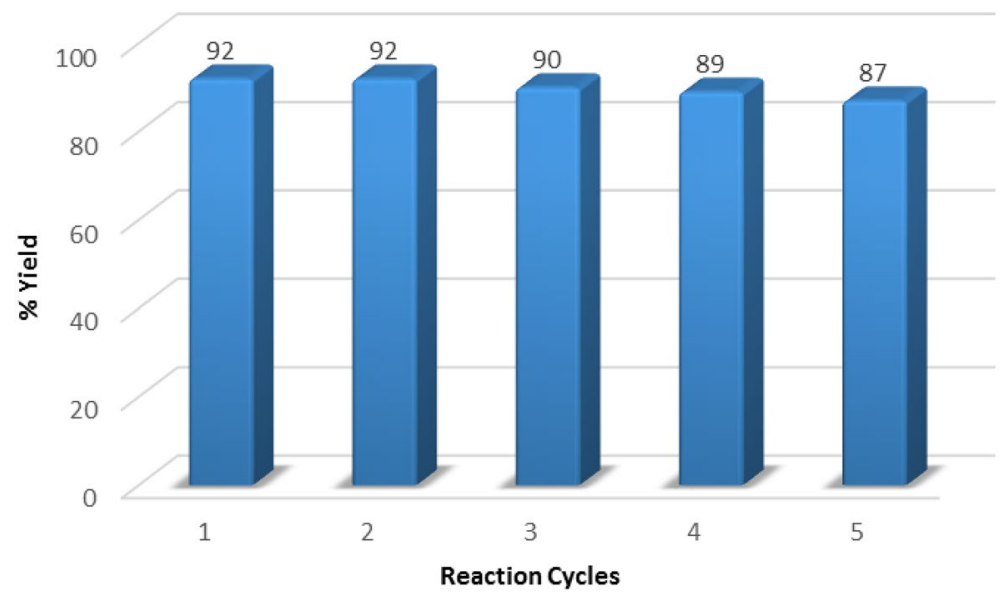

Figure 12. Reusability of catalyst for model reaction.

progress the reaction for approximately $50 \%$, the $\mathrm{Fe}_{3} \mathrm{O}_{4} @ H K U S T-1$ catalyst has been separated from the reaction mixture with an external magnet and then, the reaction performed for another $60 \mathrm{~min}$. In interesting notice, without the catalyst, the reaction was not carried out that it was monitored by TLC (Fig. 13). A good agreement with ICP results and shows that no leaching of $\mathrm{Cu}$ or MOF shell structures have been happened during the 1,3-dipolar cycloaddition reaction. Also, to elucidate the stability of catalyst, after five cycles in the model reaction, any structural changes of catalyst were studied by FT-IR, SEM and ICP techniques. It is clearly evident from the FT-IR spectrum of the 5th reused catalyst that no significant changes in the frequencies, intensities and shapes of absorption bands were observed (Fig. S1). Moreover, the morphology and size of 5th reused catalyst has been investigated bey SEM technique (Fig. S2). The SEM image of resued catalyst (Fig. S2b) was aproximately similar with the SEM image of fersh catalyst (Fig. S2a) and there are not any significant differences in size and morphlogy. Besides, as mentioned in previous sections, the ICP-OES analysis showed that the amount of $\mathrm{Cu}$ in reused catalyst is $3.497 \mathrm{wt} \%$ that the decrease is very low and it can be ignored. Based on this valuable obtained data, no significant leaching of MOF was obsedrved from the surface of $\mathrm{Fe}_{3} \mathrm{O}_{4} \mathrm{NPs}$.

To show the merit of present study compared to previously reported ones by using copper-based catalyst, the effect of our magnetic CuMOF catalyst has been compared with other $\mathrm{Cu}$ catalysts in the reaction of benzyl bromide, sodium azide and phenylacetylene (Table 3). Up to now, different homogeneous and heterogeneous $\mathrm{Cu}$ catalysts have been used for the azide-alkyne cycloaddition reaction (entries 1-8), but some of them suffer from long reaction time (entries 1-5), using hazardous solvent and reaction conditions (entries 1,3,4 and 7) and more importantly problems to reuse the catalyst (entries $1-3$, and 5). Due to the heterogeneous nature and magnetic 


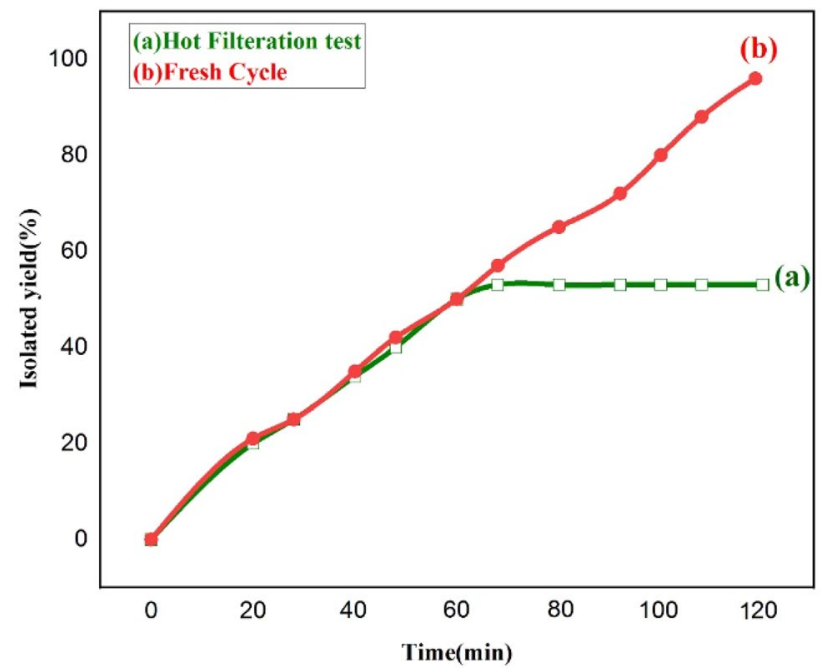

Figure 13. Time-dependent correlation of the product yield in hot filtration test.

\begin{tabular}{|c|c|c|c|c|c|c|}
\hline Entry & Catalyst & Solvent & Temp. (oC) & Time (h) & Yield (\%) ${ }^{\mathrm{a}}$ & Refs. \\
\hline 1 & Nano $\mathrm{CuO}$ & $\mathrm{H}_{2} \mathrm{O} / \mathrm{THF}$ & 60 & 24 & 95 & 4 \\
\hline 2 & Graphite-Cu NPs & $\mathrm{H} 2 \mathrm{O} / \mathrm{MeOH}$ & 70 & 12 & 91 & 69 \\
\hline 3 & GO-Metformin- $\mathrm{Cu}$ & $\mathrm{H}_{2} \mathrm{O}$ & $\mathrm{rt}$ & 0.5 & 96 & 70 \\
\hline 4 & $\mathrm{Cu}$ polymer- $\mathrm{Fe}_{3} \mathrm{O}_{4}$ & $\mathrm{H}_{2} \mathrm{O}$ & 50 & 2.0 & 96 & 71 \\
\hline 5 & $\mathrm{Cu}-\mathrm{MWCNT} @ \mathrm{Fe}_{3} \mathrm{O}_{4}$ & $\mathrm{H}_{2} \mathrm{O}$ & 50 & 1.0 & 99 & 72 \\
\hline 6 & CuII-Hydrotalcite & $\mathrm{MeCN}$ & $\mathrm{rt}$ & 3.0 & 86 & 73 \\
\hline 7 & $\mathrm{Cu} / \mathrm{SiO}_{2}$ & THF & $\mathrm{rt}$ & 2.0 & 99 & 74 \\
\hline 8 & Thiourea $\mathrm{CuCl}$ & Solvent-free & $\mathrm{rt}$ & 2.0 & 96 & \begin{tabular}{|l|l}
75 \\
\end{tabular} \\
\hline 9 & $\mathrm{Fe}_{3} \mathrm{O}_{4} @ \mathrm{MOF}$ & $\mathrm{H}_{2} \mathrm{O}$ & 100 & 2.0 & 92 & This study \\
\hline
\end{tabular}

Table 3. Comparison of $\mathrm{Fe}_{3} \mathrm{O}_{4} @ H K U S T-1$ catalyst with other copper catalysts for the synthesis of

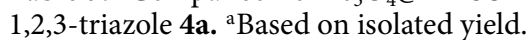

properties of our catalyst, it can be separated from the reaction mixture by a simple external magnet and it can catalyze the 1,3-diplar cycloaddition reaction in shorter reaction time and greener condition (use water, entry 9).

\section{Conclusion}

In summary, a new magnetic MOF catalyst based on copper has been described for the synthesis of 1,2,3-triazole derivatives via the three component condensation reaction of various benzyl/alkyl halides, sodium azide and different phenyl acetylene derivatives. However, this reaction has been carried out with various homogeneous and heterogeneous $\mathrm{Cu}$ catalysts and also this reaction is famed to $\mathrm{Cu}$ azide-alkyne cycloaddition reaction, but this study is the first report for the use of magnetic CuMOF in the azide-alkyne cycloaddition reaction. Surprisingly, this catalyst can catalyze the synthesis of 1,2,3-triazole derivatives in short reaction time, good to excellent yields and more importantly in the presence of water as a green and environmentally friendly solvent.

\section{Experimental}

General. All the materials and reagents were bought from Merck and Sigma-Aldrich companies without any further purification. NMR spectra were obtained with a Bruker AC instrument at $300 \mathrm{MHz}$ in DMSO-d6. Mass spectra were obtained with a Varian Mat CH-7 at 70 eV. FT-IR spectra were recorded with a Nicolet Avatar 370 FT-IR spectrometer. TGA was performed with a Shimadzu thermogravimetric analyzer (TG- 50) under air atmosphere at a heating rate of $10{ }^{\circ} \mathrm{C} \mathrm{min}^{-1}$. The crystal structure of the catalyst was analyzed using XRD with a Bruker D8 ADVANCE diffractometer using a Cu target $(\lambda=1.54 \AA)$. TEM was performed with a Leo $912 \mathrm{AB}$ $(120 \mathrm{kV})$ microscope (Zeiss, Germany). ICP analysis was carried out with a Varian VISTA- PRO, CCD (Australia). Elemental compositions were determined with EDX analysis (model 7353, Oxford Instruments, UK), with $133 \mathrm{eV}$ resolute ion. The magnetic property of the catalyst was measured using VSM (model 7400, Lake Shore). Melting points of products were recorded with an Electrothermal type 9200 melting point apparatus.

Preparation of catalyst $\left(\mathrm{Fe}_{3} \mathrm{O}_{4}\right.$ @HKUST-1). The catalyst has been prepared according to the literature ${ }^{55,56}$. At the outset, the $\mathrm{Fe}_{3} \mathrm{O}_{4} \mathrm{MNPs}$ have been prepared by using $\mathrm{FeCl}_{3}$ and hydrothermal process ${ }^{55}$, and then, the surface of these MNPs has been modified by mercaptoacetic acid and finally, these modified MNPs 
have been coated with HKUST-1 MOF by a versatile layer-by-layer assembly method and using copper acetate and 1,3,5-benzenetricarboxylic acid (H3-BTC) (Fig. 1) ${ }^{56}$.

General procedure for the synthesis of products 4a-k. To a mixture of phenyl acetylene derivatives $(1.0 \mathrm{mmol})$, benzyl/alkyl halide $(1.0 \mathrm{mmol})$ and sodium azide $(1.2 \mathrm{mmol})$, in $10 \mathrm{~mL}$ water, $30 \mathrm{mg}(1.8 \mathrm{~mol} \%)$ of $\mathrm{Fe}_{3} \mathrm{O}_{4} @$ HKUST-1 catalyst was added and refluxed for the time mentioned in Table 2. The progress of the reaction was monitored by TLC and upon the completion the reaction, the reaction mixture was diluted with ethyl acetoacetate and the $\mathrm{Fe}_{3} \mathrm{O}_{4} @$ HKUST-1 catalyst was separated by an external magnet. Next, the organic part was separated from the water and it was dried on anhydrous $\mathrm{Na}_{2} \mathrm{SO}_{4}$ and after solvent evaporation, the final products have been purified by recrystallization from ethanol to obtain the compounds $4 \mathbf{a}-\mathbf{k}$.

Received: 16 July 2021; Accepted: 20 September 2021

Published online: 15 October 2021

\section{References}

1. Teymoori, E., Davoodnia, A., Khojastehnezhad, A. \& Hosseininasab, N. Nanomagnetic organic-inorganic hybrid (CuFe2O4@ Si-Imid-PMo): an efficient green catalyst for the Synthesis of 2, 4, 5-trisubstituted imidazoles. Iran. Chem. Commun. 7, 271-282 (2019).

2. Moeinpour, F. \& Khojastehnezhad, A. Polyphosphoric acid supported on $\mathrm{Ni}_{0.5} \mathrm{Zn}_{0.5} \mathrm{Fe}_{2} \mathrm{O}_{4}$ nanoparticles as a magnetically-recoverable green catalyst for the synthesis of pyranopyrazoles. Arab. J. Chem. 10, 3468-3474 (2017).

3. Khojastehnezhad, A., Maleki, B., Karrabi, B. \& Seresht, E. R. Synthesis of highly functionalized piperidines using polyphosphoric acid supported on silica-coated magnetic nanoparticles. Org. Prep. Proced. Int. 49, 338-345 (2017).

4. Hosseininasab, N., Davoodnia, A., Rostami-Charati, F. \& Khojastehnezhad, A. Preparation, characterization, and first catalytic application of a novel phosphotungstic acid-containing ionic liquid immobilized on $\mathrm{CuFe}_{2} \mathrm{O}_{4} @ \mathrm{SiO}_{2}$ magnetic nanoparticles in the synthesis of 1H-pyrazolo [1, 2-b] phthalazine-5, 10-diones. Russ. J. Gen. Chem. 87, 2436-2443 (2017).

5. Javid, A. et al. Synthesis of pyranopyrazoles using a magnetically separable modified preyssler heteropoly acid. Org. Prep. Proc. Int. 48, 377-384 (2016).

6. Maleki, B. et al. Caesium carbonate supported on hydroxyapatite-encapsulated $\mathrm{Ni}_{0.5} \mathrm{Zn}_{0.5} \mathrm{Fe}_{2} \mathrm{O}_{4}$ nanocrystallites as a novel magnetically basic catalyst for the one-pot synthesis of pyrazolo [1, 2-b] phthalazine-5, 10-diones. Appl. Organomet. Chem. 29, 290-295 (2015).

7. Maleki, B. et al. Silica-coated magnetic NiFe 2 O 4 nanoparticles-supported H 3 PW 12 O 40; synthesis, preparation, and application as an efficient, magnetic, green catalyst for one-pot synthesis of tetrahydrobenzo [b] pyran and pyrano [2, 3-c] pyrazole derivatives. Res. Chem. Intermed. 42, 3071-3093 (2016).

8. Jin, J. et al. Self-Assembly of Uniform Spherical Aggregates of Magnetic Nanoparticles through $\pi-\pi$ Interactions. Angew. Chem. Int. 113, 2193-2196 (2001).

9. Bae, J.-E. et al. The effect of static magnetic fields on the aggregation and cytotoxicity of magnetic nanoparticles. Biomaterials 32, 9401-9414 (2011).

10. Eshghi, H. et al. Preyssler heteropolyacid supported on silica coated NiFe2O4 nanoparticles for the catalytic synthesis of bis (dihydropyrimidinone) benzene and 3, 4-dihydropyrimidin-2 (1H)-ones. Chin. J. Catal. 36, 299-307 (2015).

11. Eshghi, H. et al. Synthesis, characterization and first application of keggin-type heteropoly acids supported on silica coated $\mathrm{NiFe}_{2} \mathrm{O}_{4}$ as novel magnetically catalysts for the synthesis of tetrahydropyridines. RSC Adv. 4, 39782-39789 (2014).

12. Eshghi, H. et al. Nanomagnetic organic-inorganic hybrid (Fe@ Si-Gu-Prs): a novel magnetically green catalyst for the synthesis of tetrahydropyridine derivatives at room temperature under solvent-free conditions. Tetrahedron 71, 436-444 (2015).

13. Maleki, B., Baghayeri, M., Abadi, S. A. J., Tayebee, R. \& Khojastehnezhad, A. Ultrasound promoted facile one pot synthesis of highly substituted pyran derivatives catalyzed by silica-coated magnetic $\mathrm{NiFe}_{2} \mathrm{O}_{4}$ nanoparticle-supported $\mathrm{H} 14$ [ $\mathrm{NaP} 5 \mathrm{~W} 30 \mathrm{O}$ 110] under mild conditions. RSC Adv. 6, 96644-96661 (2016).

14. Khojastehnezhad, A., Rahimizadeh, M., Moeinpour, F., Eshghi, H. \& Bakavoli, M. Polyphosphoric acid supported on silica-coated $\mathrm{NiFe} 2 \mathrm{O} 4$ nanoparticles: An efficient and magnetically-recoverable catalyst for N-formylation of amines. Compt. Rend. Chim. 17, 459-464 (2014).

15. Sonei, S., Taghavi, F., Khojastehnezhad, A. \& Gholizadeh, M. Copper-Functionalized Silica-Coated Magnetic Nanoparticles for an Efficient Suzuki Cross-Coupling Reaction. ChemistrySelect 6, 359-368 (2021).

16. Simeonidis, K. et al. Controlling magnetization reversal and hyperthermia efficiency in core-shell iron-iron oxide magnetic nanoparticles by tuning the interphase coupling. ACS Appl. Mater. Int. 3, 4465-4476 (2020).

17. Khojastehnezhad, A., Moeinpour, F. \& Javid, A. NiFe2O4@ SiO2-PPA nanoparticle: A green nanocatalyst for the synthesis of $\beta$-acetamido ketones. Polycyc. Aromat. Comp. (2017).

18. Rahimizadeh, M. et al. Nanomagnetically modified ferric hydrogen sulfate $\left(\mathrm{NiFe}_{2} \mathrm{O}_{4} @ \mathrm{SiO}_{2}-\mathrm{FHS}\right)$ : A reusable green catalyst for the synthesis of highly functionalized piperidine derivatives. J. Iran. Chem. Soc. 12, 839-844 (2015).

19. Ke, F., Qiu, L.-G., Yuan, Y.-P., Jiang, X. \& Zhu, J.-F. Fe 3 O 4@ MOF core-shell magnetic microspheres with a designable metalorganic framework shell. J. Mater. Chem. 22, 9497-9500 (2012).

20. Guo, Y. et al. Synthesis of magnetic core-shell carbon dot@ MFe 2 O 4 (M= Mn, Zn and Cu) hybrid materials and their catalytic properties. J. Mater. Chem. 4, 4044-4055 (2016).

21. Hou, C. et al. Covalent organic framework-functionalized magnetic CuFe2O4/Ag nanoparticles for the reduction of 4-nitrophenol. Nanomaterials 10, 426 (2020).

22. Wang, H.-H. et al. Porous MOF with highly efficient selectivity and chemical conversion for CO2. ACS Appl. Mater. Int. 9, 17969-17976 (2017).

23. Lu, G. et al. Imparting functionality to a metal-organic framework material by controlled nanoparticle encapsulation. Nat. Chem. 4, 310-316 (2012).

24. Zhou, H.-C., Long, J. R. \& Yaghi, O. M. Introduction to metal-organic frameworks. Chem. Rev. 112, 673-674 (2012).

25. Ma, X., Chai, Y., Li, P. \& Wang, B. Metal-organic framework films and their potential applications in environmental pollution control. Acc. Chem. Res. 52, 1461-1470 (2019).

26. Luo, Z. et al. Metal-organic framework (MOF)-based nanomaterials for biomedical applications. Curr. Med. Chem. 26, 3341-3369 (2019).

27. Zhu, X. et al. Metal-organic framework (MOF): a novel sensing platform for biomolecules. Chem. Com. 49, 1276-1278 (2013).

28. Gao, F. et al. NiO@Ni-MOF nanoarrays modified Ti mesh as ultrasensitive electrochemical sensing platform for luteolin detection. Talanta 215, 120891 (2020). 
29. Herbst, A., Khutia, A. \& Janiak, C. Brønsted instead of Lewis acidity in functionalized MIL-101Cr MOFs for efficient heterogeneous (nano-MOF) catalysis in the condensation reaction of aldehydes with alcohols. Inorg. Chem. 53, 7319-7333 (2014).

30. Yadav, S. et al. Magnetic metal organic framework composites: structurally advanced catalytic materials for organic transformations. Mater. Adv. (2021).

31. Butova, V. V., Pankin, I. A., Burachevskaya, O. A., Vetlitsyna-Novikova, K. S. \& Soldatov, A. V. J. I. C. A. New fast synthesis of MOF-801 for water and hydrogen storage: Modulator effect and recycling options. Inorg. Chem. Acta 514, 120025 (2021).

32. Ma, R., Yang, P., Ma, Y. \& Bian, F. Facile synthesis of magnetic hierarchical core-shell structured $\mathrm{Fe}_{3} \mathrm{O}_{4} @$ PDA-Pd@ MOF nanocomposites: Highly integrated multifunctional catalysts. ChemCatChem 10, 1446-1454 (2018).

33. Li, W., Wu, X., Li, S., Tang, W. \& Chen, Y. Magnetic porous Fe3O4/carbon octahedra derived from iron-based metal-organic framework as heterogeneous Fenton-like catalyst. Appl. Surf. Sci. 436, 252-262 (2018).

34. Yang, S., Zhang, Z. H., Chen, Q., He, M. Y. \& Wang, L. Magnetically recyclable metal-organic framework@ $\mathrm{Fe}_{3} \mathrm{O}_{4}$ compositecatalyzed facile reduction of nitroarene compounds in aqueous medium. Appl. Organomet. Chem. 32, e4132 (2018).

35. Huisgen, R. 1, 3-dipolar cycloadditions. Past and future. Angew. Chem. Int. 2, 565-598 (1963).

36. Tornøe, C. W., Christensen, C. \& Meldal, M. Peptidotriazoles on solid phase:[1, 2,3]-triazoles by regiospecific copper (I)-catalyzed 1,3-dipolar cycloadditions of terminal alkynes to azides. J. Org. Chem. 67, 3057-3064 (2002).

37. Rostovtsev, V. V., Green, L. G., Fokin, V. V. \& Sharpless, K. B. A stepwise huisgen cycloaddition process: copper (I)-catalyzed regioselective "ligation" of azides and terminal alkynes. Angew. Chem. Int. 114, 2708-2711 (2002).

38. Meldal, M. \& Tornøe, C. W. Cu-catalyzed azide-alkyne cycloaddition. Chem. Rev. 108, 2952-3015 (2008).

39. Pessel, F., Billault, I. \& Scherrmann, M.-C. Total synthesis of triazole-linked C-glycosyl flavonoids in alternative solvents and environmental assessment in terms of reaction, workup and purification. Green Chem. 18, 5558-5568 (2016).

40. Juríček, M., Kouwer, P. H. \& Rowan, A. E. Triazole: a unique building block for the construction of functional materials. Chem. Com. 47, 8740-8749 (2011).

41. Rodionov, V. O., Fokin, V. V. \& Finn, M. Mechanism of the ligand-free CuI-catalyzed azide-alkyne cycloaddition reaction. Angew. Chem. Int. 117, 2250-2255 (2005).

42. Zhang, W., He, X., Ren, B., Jiang, Y. \& Hu, Z. Cu (OAc)2.H2O-An efficient catalyst for Huisgen-click reaction in supercritical carbon dioxide. Tetrahedron Lett. 56, 2472-2475 (2015).

43. Song, Y.-J. et al. Nanocrystalline copper oxide (II)-catalyzed alkyne-azide cycloadditions. Bull. Korean Chem. Soc. 29, 1561-1564 (2008).

44. Pericherla, K., Jha, A., Khungar, B. \& Kumar, A. Copper-catalyzed tandem azide-alkyne cycloaddition, ullmann type C-N coupling, and intramolecular direct arylation. Org. Lett. 15, 4304-4307 (2013).

45. Ali, A. A., Chetia, M. \& Sarma, D. Urea assisted copper (I)-catalyzed azide-alkyne cycloaddition reactions in water. Tetrahedron Lett. 57, 1711-1714 (2016).

46. Kaboudin, B., Mostafalu, R. \& Yokomatsu, T. Fe 3 O 4 nanoparticle-supported Cu (II)- $\beta$-cyclodextrin complex as a magnetically recoverable and reusable catalyst for the synthesis of symmetrical biaryls and 1,2,3-triazoles from aryl boronic acids. Green Chem. 15, 2266-2274 (2013).

47. Zirak, M. \& Jamali Garegeshlagi, E. Picolinimidoamide-Cu (II) complex anchored on Fe3O4@ SiO2 core-shell magnetic nanoparticles: an efficient reusable catalyst for click reaction. J. Coord. Chem. 71, 1168-1179 (2018).

48. Khojastehnezhad, A., Bakavoli, M., Javid, A., Siuki, M. M. K. \& Shahidzadeh, M. Synthesis, characterization, and investigation of catalytic activity of copper (II) porphyrin graphene oxide for azide-alkyne cycloaddition. Res. Chem. Intermed. 2019, 1-13 (2019).

49. Deilam, R., Moeinpour, F. \& Mohseni-Shahri, F. S. Catalytic performance of $\mathrm{Cu}$ (II)-supported graphene quantum dots modified $\mathrm{NiFe} 2 \mathrm{O} 4$ as a proficient nano-catalyst in the synthesis of 1, 2, 3-triazoles. Monatsh. Chem. 151, 1153-1162 (2020).

50. Ghadamyari, Z., Khojastehnezhad, A., Seyedi, S. M. \& Shiri, A. Co (II)-porphyrin immobilized on graphene oxide: An efficient catalyst for the Beckmann rearrangement. ChemistrySelect 4, 10920-10927 (2019).

51. Keyhaniyan, M., Khojastehnezhad, A., Eshghi, H. \& Shiri, A. Magnetic covalently immobilized nickel complex: A new and efficient method for the Suzuki cross-coupling reaction. Appl. Organomet. Chem., e6158.

52. Ghadamyari, Z., Khojastehnezhad, A., Seyedi, S. M., Taghavi, F. \& Shiri, A. Graphene oxide functionalized Zn (II) Salen complex: An efficient and new route for the synthesis of 1, 2, 3-triazole derivatives. ChemistrySelect 5, 10233-10242 (2020).

53. Keyhaniyan, M., Shiri, A., Eshghi, H. \& Khojastehnezhad, A. Synthesis, characterization and first application of covalently immobilized nickel-porphyrin on graphene oxide for Suzuki cross-coupling reaction. New J. Chem. 42, 19433-19441 (2018).

54. Chui, S.S.-Y., Lo, S.M.-F., Charmant, J. P., Orpen, A. G. \& Williams, I. D. A chemically functionalizable nanoporous material [Cu3 (TMA) $\left.2\left(\mathrm{H}_{2} \mathrm{O}\right) 3\right]$ n. Science 283, 1148-1150 (1999).

55. Xuan, S., Wang, F., Wang, Y.-X.J., Jimmy, C. Y. \& Leung, K.C.-F. Facile synthesis of size-controllable monodispersed ferrite nanospheres. J. Mater. Chem. 20, 5086-5094 (2010).

56. Sun, X., Gao, G., Yan, D. \& Feng, C. Synthesis and electrochemical properties of Fe3O4@ MOF core-shell microspheres as an anode for lithium ion battery application. Appl. Surf. Sci. 405, 52-59 (2017).

57. Li, J., Gao, H., Tan, L., Luan, Y. \& Yang, M. Superparamagnetic core-shell metal-organic framework Fe3O4/Cu3 (BTC) 2 microspheres and their catalytic activity in the aerobic oxidation of alcohols and olefins. Eur. J. Inorg. Chem. 2016, 4906-4912 (2016).

58. Yu, B. Y. \& Kwak, S.-Y. Assembly of magnetite nanocrystals into spherical mesoporous aggregates with a 3-D wormhole-like pore structure. J. Mater. Chem. 20, 8320-8328 (2010).

59. Nejadshafiee, V. et al. Magnetic bio-metal-organic framework nanocomposites decorated with folic acid conjugated chitosan as a promising biocompatible targeted theranostic system for cancer treatment. Mater. Sci. Eng. 99, 805-815 (2019).

60. Mohammadinezhad, A. \& Akhlaghinia, B. Engineered superparamagnetic core-shell metal-organic frame-work $\left(\mathrm{Fe}_{3} \mathrm{O}_{4} @ \mathrm{Ni}-\mathrm{Co}-\right.$ BTC NPs) with enhanced photocatalytic activity for selective aerobic oxidation of alcohols under solar light irradiation. Catal. Lett. 2020, 1-17 (2020).

61. El Ayouchia, H. B., Bahsis, L., Anane, H., Domingo, L. R. \& Stiriba, S.-E. Understanding the mechanism and regioselectivity of the copper (i) catalyzed [3+ 2] cycloaddition reaction between azide and alkyne: A systematic DFT study. RSC Adv. 8, 7670-7678 (2018).

62. Liang, L. \& Astruc, D. The copper (I)-catalyzed alkyne-azide cycloaddition (CuAAC) "click" reaction and its applications. An overview. Coordination Chem. Rev. 255, 2933-2945 (2011).

63. Sharghi, H., Shiri, P. \& Aberi, M. Five-membered N-heterocycles synthesis catalyzed by nano-silica supported copper (II)-2-imino-1, 2-diphenylethan-1-ol complex. Catal. Lett. 147, 2844-2862 (2017).

64. Wang, Z. X. \& Zhao, Z. G. Synthesis of 1, 4-disubstituted 1, 2, 3-triazoles via a three-component reaction in water in the presence of cux (X= Cl, I). J. Heterocycl. Chem. 44, 89-92 (2007).

65. Sharghi, H., Khalifeh, R. \& Doroodmand, M. M. Copper nanoparticles on charcoal for multicomponent catalytic synthesis of 1,2, 3-Triazole derivatives from benzyl halides or alkyl halides, terminal alkynes and sodium azide in water as a "Green" solvent. $A d v$. Synth. Catal. 351, 207-218 (2009).

66. Hasanpour, Z. et al. Efficient multicomponent synthesis of 1, 2, 3-triazoles catalyzed by $\mathrm{Cu}$ (II) supported on PEI@Fe $\mathrm{O}_{4} \mathrm{MNPs}$ in a water/PEG 300 system. Turk. J. Chem. 41 (2017).

67. Bonyasi, R., Gholinejad, M., Saadati, F. \& Nájera, C. Copper ferrite nanoparticle modified starch as a highly recoverable catalyst for room temperature click chemistry: Multicomponent synthesis of 1, 2, 3-triazoles in water. New J. Chem. 42, 3078-3086 (2018). 
68. Ghodsinia, S. S., Akhlaghinia, B. \& Jahanshahi, R. Direct access to stabilized Cu I using cuttlebone as a natural-reducing support for efficient CuAAC click reactions in water. RSC Adv. 6, 63613-63623 (2016).

69. d'Halluin, M. et al. Graphite-supported ultra-small copper nanoparticles-Preparation, characterization and catalysis applications. Carbon 93, 974-983 (2015).

70. Eftekhar, M. \& Raoufi, F. J. P. A. C. Synthesis, characterization and first application of graphene oxide functionalized Cu (II) complex for the synthesis of 1, 2, 3-triazole derivatives. Polycyc. Aromat. Comp. 2021, 1-13 (2021).

71. Zohreh, N., Hosseini, S. H., Pourjavadi, A. \& Bennett, C. J. A. O. C. Immobilized copper (II) on nitrogen-rich polymer-entrapped $\mathrm{Fe}_{3} \mathrm{O}_{4}$ nanoparticles: A highly loaded and magnetically recoverable catalyst for aqueous click chemistry. Appl. Organomet. Chem. 30, 73-80 (2016)

72. Shaabani, A., Afshari, R., Hooshmand, S. E., Tabatabaei, A. T. \& Hajishaabanha, F. J. R. A. Copper supported on MWCNT-guanidine acetic acid@ $\mathrm{Fe}_{3} \mathrm{O}_{4}$ : Synthesis, characterization and application as a novel multi-task nanocatalyst for preparation of triazoles and bis (indolyl) methanes in water. RSC Adv. 6, 18113-18125 (2016).

73. Namitharan, K., Kumarraja, M. \& Pitchumani, K. CuII-Hydrotalcite as an efficient heterogeneous catalyst for Huisgen [3+2] cycloaddition. Chem. Eur. J. 15, 2755-2758 (2009).

74. Jumde, R. P., Evangelisti, C., Mandoli, A., Scotti, N. \& Psaro, R. Aminopropyl-silica-supported Cu nanoparticles: An efficient catalyst for continuous-flow Huisgen azide-alkyne cycloaddition (CuAAC). J. Catal. 324, 25-31 (2015).

75. Barman, M. K., Sinha, A. K. \& Nembenna, S. An efficient and recyclable thiourea-supported copper (I) chloride catalyst for azide-alkyne cycloaddition reactions. Green Chem. 18, 2534-2541 (2016).

\section{Acknowledgements}

The authors gratefully acknowledge the partial support of this study by Ferdowsi University of Mashhad (3/54199).

\section{Author contributions}

E.A.,: Visualization, Formal analysis, Methodology. A.S.,: Funding acquisition, Supervision. A.K., Writing original draft, Formal analysis, Writing-review and editing.

\section{Competing interests}

The authors declare no competing interests.

\section{Additional information}

Supplementary Information The online version contains supplementary material available at https://doi.org/ 10.1038/s41598-021-00012-3.

Correspondence and requests for materials should be addressed to A.S.

Reprints and permissions information is available at www.nature.com/reprints.

Publisher's note Springer Nature remains neutral with regard to jurisdictional claims in published maps and institutional affiliations.

(c) (i) Open Access This article is licensed under a Creative Commons Attribution 4.0 International License, which permits use, sharing, adaptation, distribution and reproduction in any medium or format, as long as you give appropriate credit to the original author(s) and the source, provide a link to the Creative Commons licence, and indicate if changes were made. The images or other third party material in this article are included in the article's Creative Commons licence, unless indicated otherwise in a credit line to the material. If material is not included in the article's Creative Commons licence and your intended use is not permitted by statutory regulation or exceeds the permitted use, you will need to obtain permission directly from the copyright holder. To view a copy of this licence, visit http://creativecommons.org/licenses/by/4.0/.

(C) The Author(s) 2021 